\title{
Jeff Golyscheff e as Dificuldades de sua Recuperação
}

\section{Walter Zanini*}

A morte interrompeu o trabalho que há longos anos Antonia Brede Golyscheff realizava na recuperação da memória de seu marido. Em outubro de 1980, um ataque do coração fulminou-a, em seu pequeno e solitário apartamento da Rua Bernard Palissy, em Paris, junto a documentos que pacientemente reunia e algumas telas e desenhos que com certeza ainda guardava.

Somente no início de 1981, em viagem à Europa, soubemos do traspasse da amiga e correspondente, de 79 anos. Não nos restou quase outra coisa senão lamentar a sua morte e as circunstâncias em que se dera. Foi-nos impossível conseguir acesso ao material que ficara atrás de uma porta lacrada e foram vãs as solicitações que fizemos a várias pessoas e a uma entidade para que acompanhassem as diligênçias judiciais. Com o passar do tempo, o silêncio acabou a tudo envolvendo e ignoramos ainda hoje o destino final do espólio. Reproduzia-se, nessa situação "in extremis", o fenômeno dramático das dispersóes e perdas que marcaram a existência do músico e pintor Jeff Golyscheff, falecido um decênio antes.

Fatores muito acima de suas próprias forças haviam destruído quase todo o seu importante passado artístico, principalmente aquele que se descnrolara em Berlim no período entre 1913 e o começo da década de 1920. Isso o levaria, em fase avançada (anos de 1960), a uma tarefa de retomada e refazimento de sua obra plástica, com a idéia de que, dessa maneira, prestava uma homenagem aos seus amigos de outrora. Em verdade, a decisão tornava-se também um ato de recuperação e justiça para consigo mesmo. Ao voltar a público depois de quarenta anos de distanciamento voluntário, Golyscheff suscitaria a maior surpresa entre seus contemporâneos berlinenses sobreviventes que de há muito o acreditavam 
desaparecido para sempre. Um movimento espontâneo tomara então forma visando a fazer ressurgir o seu nome.

No que concerne ao músico - violinista admirável aos oito $\operatorname{anos}^{1}$-, o achado da partitura extraviada do "Trio para cordas", de 1914, pelo Instituto de Musicologia de Colônia e sua divulgação pela rádio alemã, no início dos anos de 1960, contribuíram decisivamente para a redescoberta do compositor. Dispõe-se hoje de um registro fundamental de sua produção - embora de teor quase exclusivamente nominal - com um ponto de partida nessa obra escrita para violino, viola e violoncelo, que o fez um dos criadores da música dodecafônica, ao lado de Joseph Mathias Hauer. A esse traba-
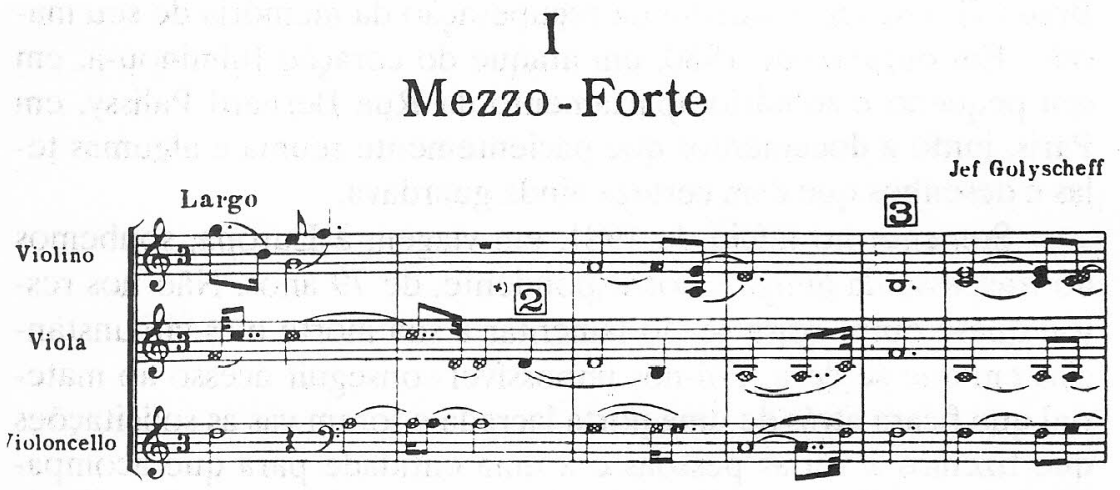

lho inovador, publicado em 1925, em que emprega o princípio da "durata", recorrendo a elementos seriais e estocásticos ${ }^{2}$, sucederam-se outras peças de vanguarda: as duas óperas escritas em 1915-6: "Cyrano de Bergerac" e "Oper"; músicas de câmara, peças de canto e o poema sinfônico com o título irreverente de Das eisige Lied, Dauer eine Stunde und 40 Minuten (contendo uma parte de características prenunciadoras do happening $)^{3}$. Num outro momento, ele comporia músicas para os primeiros filmes sonoros alemães e russos, a exemplo de Igdenbu der grosse Jäger; de 1931. Golyscheff fizera o conhecimento de Pudovkin e Eisenstein ${ }^{4}$. Igualmente, é ele o autor da "Antisinfonia", cujas dissonâncias aturdiram o público em evento do Club Dada de Berlim, em 1919 (descrito por Hausmann $)^{5}$. Entre os seus maiores incentivadores achava-se Ferruccio Busoní. É uma infelicidade que, à exceção do "Trio para cordas", nenhuma outra de suas partituras subsistisse (ou reaparecesse). 
Não é menos trágico o que sucedeu à sua pintura - arte em que dera os primeiros passos em 1903, estimulado por seu pai, um amigo de Kandinsky -, assim como a processos de ponta que desenvolveu, como assemblages, colagens e móbiles construídos com carretéis e fios de aço - a que adaptaria o princípio da "durata" ("aglomeração de pequenas dimensões na obra" ou "dimensões que não se repetem num conjunto"). Obras que expusera na Unbekannte Archïtekturzeichnungen, em 1919, por iniciativa da associação berlinense Arbeitsrat für Kunst ("Comitê de trabalho para a Arte"), entidade predecessora da Bauhaus, sem dúvida não são mais existentes 7 . Obras que apresentara nas mostras itinerantes da

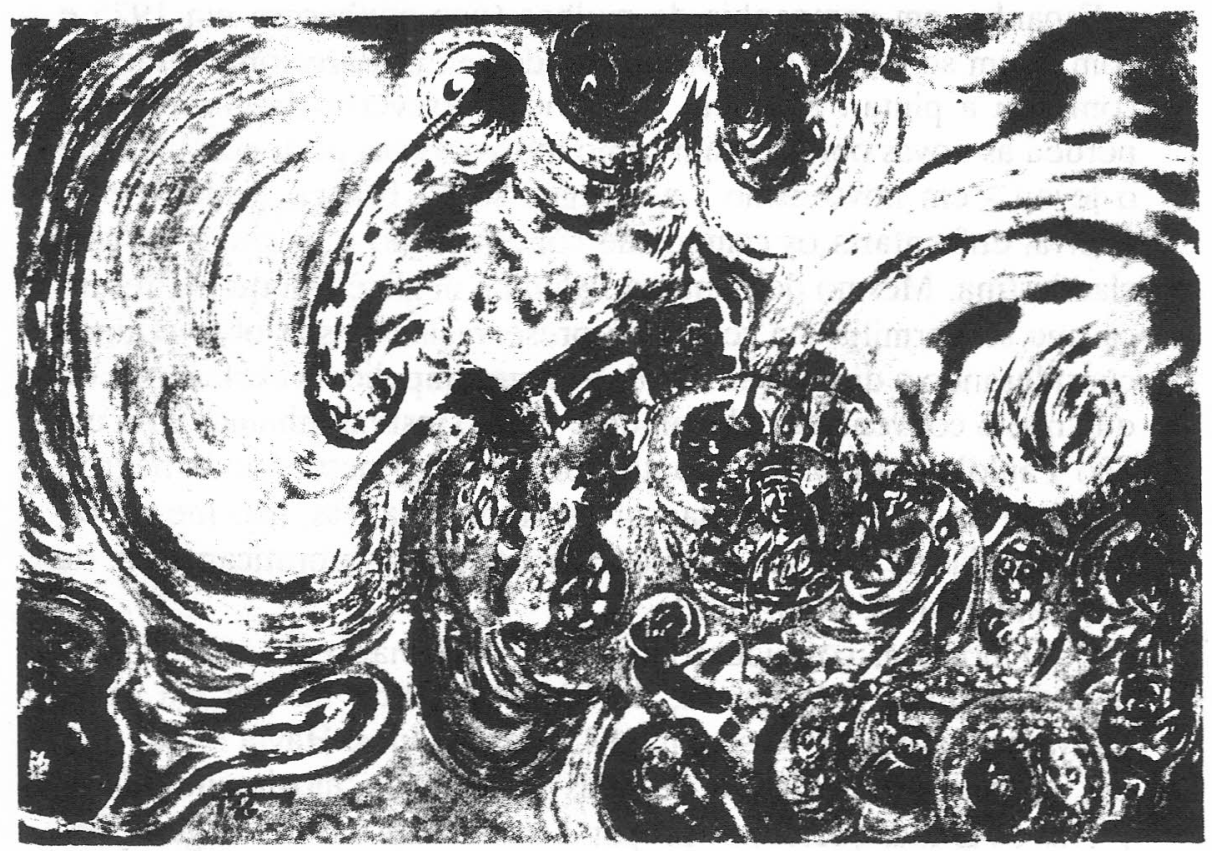

Novembergruppe, de que era membro fundador, foram extraviadas ou definitivamente perdidas. Obras que exibira na Russische Kunst, em Hanover (ao lado de Archipenko, Chagall, Kandinsky e Jawlensky) em 1921 e outras, presentes na Rheinische Sezession, em Dusseldorf, a convite de Max Ernst e na Kunsthalle de Hamburgo (com Barlach) em .1922, não ressurgiram em nenhum lugar. Mais tarde, obras que estavam em poder de Herbert Eimert e do pintor 
Bruno Goller, pereceram nos bombardeios da II Guerra. Sem paralelo, entretanto, é a façanha de que se desincumbiu o órgão policial nazista "SS", fazendo desaparecer os 200 trabalhos da primeira grande exposição individual que ele se aprestava a inaugurar em Berlim, en abril de 1933, assim como toda a documentação do catálogo ${ }^{8}$. Na mesma ocasião, apreenderam-se as suas peças musicais. Esse seqüestro foi "legitimado" na forma que era corrente - e de que foram vítimas muitos outros artistas -, ou seja, sob a alegação de que se tratava de "arte degenerada". E, ademais, ele era judeu.

Conseguindo escapar da Alemanha de Hitler, nesse mesmo mês, Golyscheff rumou para Portugal (Lisboa) e logo a seguir para a Espanha, em companhia da mulher (que conhecera em 1925 e com quem se casara em 1931), fixando-se em Barcelona, onde recomeçou a pintar. Mas, em 1938, nos entreveros da guerra civil, perdeu as novas obras (assim como todos os seus pertences). $\mathrm{O}$ que o levou - em novo exílio - a refugiar-se na França, onde, com a guerra, enfrentaria os campos de concentração e os riscos da vida clandestina. Mesmo descontando alguma negligência ou indiferença que se permitia em relação à preservação de sua obra e ainda considerando a disposição de ser às vezes impelido a desfazer-se do que não o convencesse plenamente (como testemunhamos aqui em São Paulo), assombra o tributo por ele pago nesses anos negros. Ao final da II Guerra, ao lançar os olhos para trás, não lhe sobravam dúvidas de que sua produção artística estava praticamente, ou em grande parte, aniquilada?

O homem, contudo sobrevivera. Originário de uma família ucraniana judia e burguesa, de Kherson, onde nasceu em 1897 , Golyscheff aproximava-se, em 1945, dos 50 anos. Havia muito que, em silêncio, despedira-se de seus colegas do movimento Dada ("Nós os Dada, queríamos preparar o caminho das novas gerações, mas atingido o objetivo, nós, os mouros, podíamos nos retirar" - é uma sua frase recorrente nos anos de 1960) e da Novembergruppe (artistas de várias tendências participavam dessa aliança: antigos expressionistas, como Nolde, Müller, Pechstein, Schmidt-Rottluff e outros, além de Feininger, Freundlich, Gropius, Belling, Gellhorn ..., ao lado dos quais expusera por breve período) ${ }^{10}$. Não atendera ao convite de Walter Gropius para uma função diversa: a de lecionar na Bauhaus de Weimar. Dissera adeus a seu amigo e discípulo 
Eimert. Decidira "desaparecer". Não era, evidentemente, o primeiro a fazer isso e a esse propósito sempre ocorrem lembranças de paradigmas extremos, como o de Rimbaud ou de um Cravan. No seu caso, tratava-se de um profundo desinteresse (ou indiferença) que tomara pela vida artística pública. Ele simplesmente voltara-se para a sua profissão de químico, que devia a estudos que realizara quando jovem ${ }^{11 .}$

Ora, uma década mais tarde, em 1956, certos perigos de guerra reapareceram na Europa. Foi aquele o ano do massacre na Hungria, da aventura militar capitalista no Canal de Suez e da ameaça soviética de despejar uma bomba atômica sobre Paris. Golyscheff, ali residente, resolveu então partir para longe e escolheu o Brasil, talvez pelas reminiscências de um cruzeiro marítimo que fizera em 1912-3. Ele chegou com a esposa nos primeiros meses de 1957, aos 60 anos, como um químico aposentado, domiciliando-se em São Paulo, onde, à exceção de alguns retornos breves à Alemanha, permaneceria até 1966, adquirindo a nacionalidade brasileira. Era um instante de sua vida em que assumiria com vigor a retomada da pintura, não havendo, entretanto, o mesmo imperativo $\mathrm{em}$ relação à música. Sob aquele primeiro aspecto, operava-se nele, efetivamente, um reencontro com o tempo perdido.

Em nosso meio, visitava muscus e exposições e acompanhava outros acontecimentos culturais, mas não declinava a sua identidade. Num dia de janeiro de 1965, ao dizer quem era, deixou-nos muito impressionados. Convidou-nos para visitar o seu apartamento no antigo Hotel Paris, na Avenida 9 de Julho, pois queria mostrar uma série de quadros. Ao chegarmos, notamos um ambiente quase imperceptivel de atelier, tal a ordem e a limpeza ali reinantes. Alguns quadros, pintados a óleo (ou a óleo e carvão) estavam dispostos nas paredes dos cômodos e ele estendia a mão para citá-los por seus títulos breves, sempre afins a circunstâncias de sua existência de múltiplas mudanças e vicissitudes. Pequenos ou médios (os maiores ultrapassavam de pouco um metro de largura), datavam de 1961 a 1964.

Convencemo-nos desde logo da importância das obras, cada qual com sua especificidade sígnica e ao mesmo tempo constituindo um conjunto de grande coerência. Sua percepção era a de um universo de profunda instabilidade, fazendo-nos penetrar um espaçotempo fluido e de vertiginosa expansão. Era criadora de paisagens 
ou complexos imaginários que implicavam aqui também soluções "atonais", livrando uma pintura que parece despontar da combinação de substâncias de um laboratório químico e nos instigando a ver, por vezes, o que seriam imaginativas equivalências de sons musicais.

Essas configurações turbilhonantes, mas de discretas vibrações tonais - de freqüentes cores marrons, rosas, amarelos e cinzas - não raro uma sucessão de círculos, em várias escalas, onde inscreve, com muito senso de humor, figuras, rostos e olhos humanos espectrais. Comparando suas novas obras às representações anteriores, embora das mais raras, e procurando a interpretação de referências que lhe haviam sido dedicadas, ficou-nos claro que sua mão continuava imantada dos segredos do fulgurante momento de seu passado. Entretanto, as restitutions, demonstrando a permanência da poética da Berlim dos anos áureos, poderiam pesar de fato e devidamente para o seu resgate? Ora, sabemos bem o que é a miséria de um mundo de arte dominado pelo mercado... Golyscheff era um puro e com o anátema de suas obras antepassadas sacrificadas ...

Em meados de 1960, ele desejava que sua pintura voltasse a ser conhecida. Ele aceitou o nosso convite e, em abril-maio de 1965, fizemos a mostra com 31 obras, no MAC-USP ${ }^{12}$.

Durante os dois meses em que cumprimos o que se poderia chamar de um ritual de visitas à sua casa, pudemos colher depoimentos vários sobre a participação que tivera na vanguarda das artes visuais e da música no ambiente cultural revolucionário e altamente politizado da Berlim dos anos Dada. Golyscheff era um homem fundamentalmente tímido, de grande amabilidade e fineza de espírito. Nem sempre nos era fácil considerar que à nossa frente se achava o músico e artista plástico das manifestaçoes Dada e o signatário do manifesto de Berlim ${ }^{13}$.

Golyscheff fôra praticamente ligado a toda a Berlim artística e intelectual. Convivera com as personagens significativas daquele tempo e era uma delas. Conhecia-as muitas vezes na intimidade, como Gropius, Hausmann, Busoni, Walden e outros. Formulava restrições a Schoenberg. Como resolvera sair de cena - dissera-nos com amargura, certa manhã: "não tenho uma palavra de ninguém". É uma queixa justa. Mas o crítico de arte Adolph Behne escreveu um texto básico e agudo sobre ele, em 1919. Eimert faria o mesmo 
anos depois, quanto ao músico. A este, Alfred Einstein dedicaria um verbete em seu dicionário de 1926 , depois repeticlo por outros autores. Não faltou a polêmica surgida nos anos 40 , devido ao ataque de Willi Schuh a Thomas Mann, motivada pelo fato de o autor

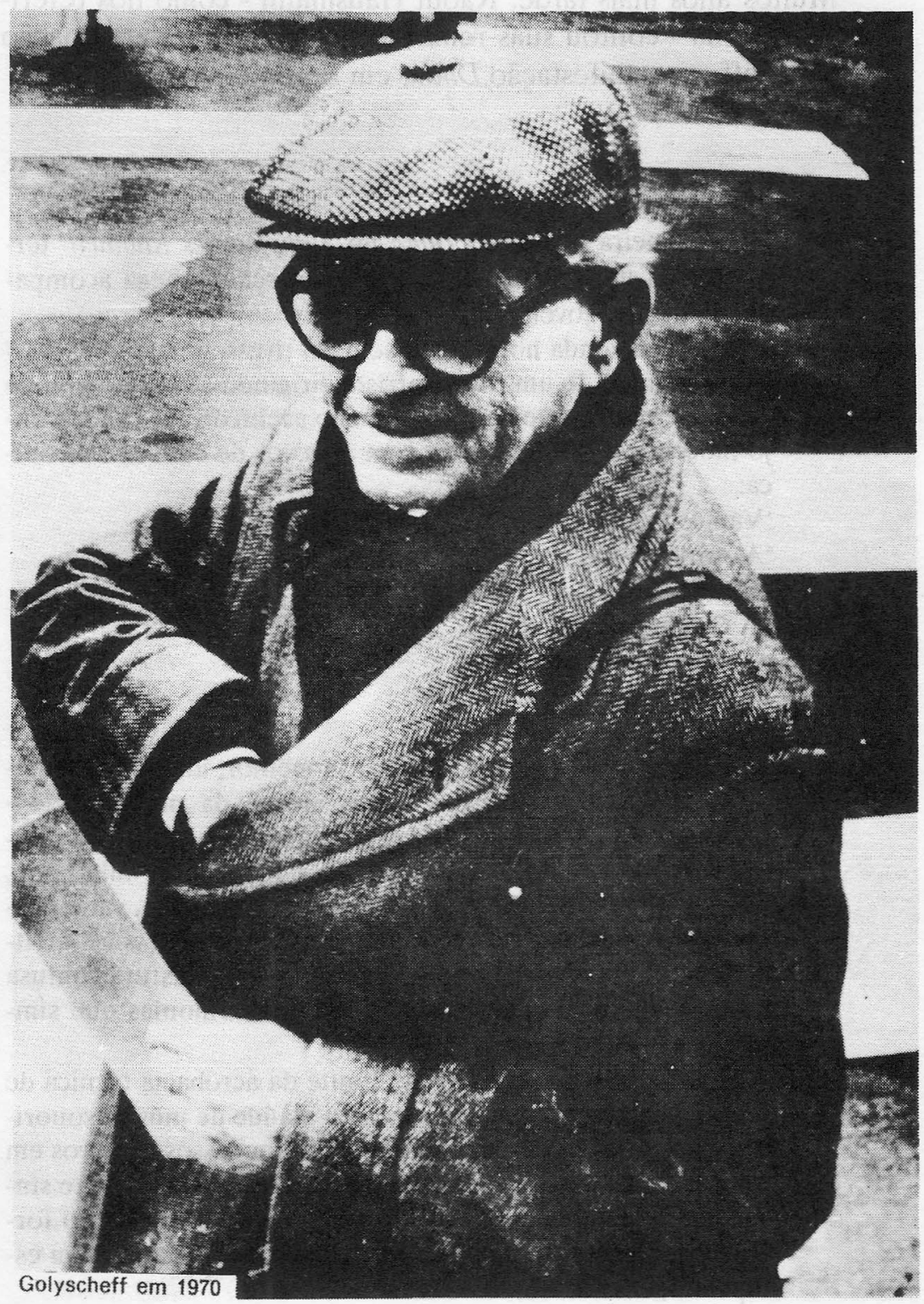


de Doktor Faustus fazer do dodecafonismo obra de um menino prodígio alemão, Adrian, esquecido de Golyscheff, que ele não podia deixar de conhecer, levando em consideração a sua intimidade com a música moderna ${ }^{14}$. Golyscheff não se envolveu na discussão.

Muitos anos mais tarde, Raoul Hausmann - como nos referimos mais acima - contou suas reminiscências sobre a participação de Golyscheff em manifestação Dada, em Berlim:

“(...)

Essa primeira exposição Dada no 'Graphisches Kabinett' termina com um grande serão onde Golyscheff chega acompanhado de uma jovem vestida de branco.

Vejo a cena ainda hoje, como se nada tivesse mudado. Golyscheff, munido de um fraco sorriso, dirigindo-se para o grande piano de cauda, fazendo um pequeno aceno de mão para o anjo inocente sentar-se e dizer com uma voz de boneca eletrônica:

'Vamos tocar'
'A Antisinfonia'
em três partes
(A Guilhotina circular)
a) 'A Injeção provocante'
b) 'A Cavidade bucal caótica'
c) 'O Super Fá dobrável'

Olhai-o, pois não podeis fazer coisa melhor, uma vez que nada entendeis de música e muito menos da música dele olhai-o bem, em toda a sua travessura, uma mistura de agressividade, de tímido, de não sei qual melancolia hilariante, olhai quem, através do jogo hábil de um anjo puro, vai estourar vossos ouvidos, arrancar vossos olhos, impor suas arritmias, suas notas penetrantes, impor-vos uma mistura confusa de sons que não querem mais ser isso, harmonias que simplesmente são: Dada.

A mecânica astuta, chegada ao limite da acrobacia técnica de pianista da jovem branca arranca ao ataúde de música sonoridades insólitas tão inesperadas que atiram vossos cérebros em transes supersônicos. Ver esse anjo inocente tocar a suíte sincopada de dissonâncias de Golyscheff causava um efeito formidável. O público, ainda sequer habituado ao Jazz, ficou estupefato, entaramelado. 
Para sempre essa imagem ficará impressa na minha memória eidofônica, para sempre eu a preservarei nos meus cones retinianos repletos, saturados de mnemo-foto-fones por mais de um meio século, para me representar esse Jeff Golyscheff que tão poucọ vi no que chamamos de realidade e que acreditava perdido para sempre.

Notas estridentes, discordantes, enxertos heteróclitos de pedaços pré-fabricados, renúncia ao hábito, nós tínhamos virado as costas à heresia e a todas as leis da razão. Ser ou não ser Dada, essa é a questão.

A sola furada de nossos sapatos nos parecia mais importante, mais presente do que todas as obras-primas de todos os tempos, pois que sobre essa sola nós marchávamos nas ruas sem ligar para nada, através dos fatos e os abismos da idiotia de uma época que havíamos marcado para sempre 15 ."

O mesmo Hausmann, anos antes, referira-se ao artista múltiplo no seu Coumier Dada

"Ignora-se em geral que a pintura Dada não fôra criada somente por Duchamp, Max Ernst, Baargeld e Schwitters. As exposições (à exceção da Feira Dada da primavera de 1920) que havíamos organizado em 1919 na Galeria J. B. Neumann e às quais participavam Grosz, Heartfield, Hannah Hoeck, eu e um jovem russo muito dotado, Jeff Golyscheff, foram ignoradas no Exterior. J. Golyscheff e eu expusemos desenhos mecânicos, xilogravuras, esculturas feitas com cartão (Hausmann) e composições realizadas com materiais heteróclitos, tais como latas de conserva, vidro, cabelos, rendas de papel (Golyscheff). Além do mais, nosso grupo expôs em bloco em 1919 e 1920 na mostra oficial da Novembergruppe... "16.

A partir de seu reaparecimento, em 1965, participamos de um trabalho que visava a reencontrar eventuais obras antigas (sem sucesso, mas o futuro sempre poderá reservar surpresas) ${ }^{17}$ e localizar documentos (com algumas recompensas). Também deram-se a conhecer no Exterior as obras de São Paulo. Lembremos que Golyscheff decidira, em 1966, retornar à Europa, residindo em Paris, onde morreria quatro anos depois, de um enfarte, aos 73 anos. Deixara entre nós um pequeno círculo de amizades, sobretudo de jovens. Na recuperação de seu nome, alguns progressos foram realizados. 
Hausmann espantou-se de saber que ele vivia no Brasil. Eimert saudou esse reencontro inesperado, depois de quatro décadas. Procuramos estabelecer contatos com críticos e dirigentes de museus e propusemos o seu ingresso no movimento Phases, de fundamentos surrealistas, a que pertencíamos, e que Edouard Jaguer aceitou com entusiasmo, incluindo-o em exposições e tratando-o em críticas. A Galeria Schwarz de Milão organizou uma sua individual, em setembro de $1970 .^{\circ}$ Golyscheff passou a ser nome selecionado em grandes mostras, como a exposição Dada comemorativa do cinqüentenário do movimento, que teve lugar na Kunsthaus de $\mathrm{Zu}$ rique e no Museu Nacional de Arte Moderna, de Paris, entre outubro de 1966 e janeiro de 1967; a exposição Avantgarde Osteeuropa 1910-1930, organizada pela Akademie der Kunste, de Berlim, em 1967; a exposição Dada, promovida pela Stadtische Galerie im Städelschen Kunstinstitut, de Franckfurt, em $1977-8$ e a exposição Dada and Surrealism Revisited, iniciativa do British Council, em 1978, em Londres.

Por outro lado, alguns museus europeus, como o Museu Nacional de Arte Moderna, de Paris, o Museu de Arte Moderna de Berlim, os Arquivos da Bauhaus, entre outros, contam hoje com trabalhos recentes do artista, assim como o MAC-USP, onde está concentrado o maior número de peças de Golyscheff. Vários estudiosos, como Herta Wescher ${ }^{18}$, demonstraram atenção pelo artista, notando-se o interesse pelo músico por parte de Detlej Gojowy, que lhe consagrou um artigo nos anos de $1970^{19}$ e selecionou seu "Trio" para os 'Concertos' do IRCAM, sobre a vida musical na U.R.S.S., de 1900 a 1930, realizados quando da grande mostra " $\mathrm{Pa}$ ris-Moscou - 1900-1930" (MNAM, Centre Georges Pompidou, Paris, 1979).

Temos confiança de que continuará a haver no Velho Continente (e quem sabe no Brasil) disposição em estudar o pintor e o músico de vanguarda. As obras do primeiro, aqui realizadas, como um presente que lança luzes reconstituintes sobre o que se extinguiu, é razão confortante - em meio ao desastre - para estimular desafios de pesquisa.

\section{NOTAS}

1. Em 1905, Golyscheff era solista da Orquestra Sinfônica de Odessa. 
2. Em depoimento ao, autor, em janeiro de 1965, em São Paulo, Golyscheff declarou: "Empreguei em 1914 a Musik-Durata também em pintura, escultura etc. A 'durata' trouxe novos caminhos. A 'durata' não é nem uma teoria, nem um novo 'ismus' mas tão-somente uma Anregung para as novas formas artísticas'.

3. A primeira parte foi executada pela Orquestra Filarmônica de Berlim, em 1920 , sob a direção de George Weller.

4. Golyscheff desenvolveu estudos de acústica cinematográfica na Alemanha, em 1924-5. Segundo ele, faltavam maiores recursos para levar adiante as pesquisas que efetuava (depoimento de 1965, cit.).

5. HAUSMANN, Raoul "A Jeff Golyscheff". Phases. Paris, n" 11, 1967, pp. $75-77$.

6. Lembrando-se de Busoni, Golyscheff declarou que ele o considerava "como um filho". Aconselhava-o a seguir o caminho solitário e inovador que escolhera. A exemplo de Richard Strauss e outros compositores, escreveu a editores recomenclando a publicação de suas partituras (depoimento de 1965, cit.).

7. Subsistiu a reprodução de um desenho, provavelmente a nanquim, intitulado "Constelação arquitetônica", que reproduzimos no artigo "Golyscheff: um passageiro clandestino exemplar". Suplemento Literário de O Estado de S.Paulo, no 715,11 abr. 1971, p.1.

8. A primeira fôra feita oito anos antes, em 1915, na Associação dos Professores Primários de Berlim (depoimento de 1965, cit.).

9. A única certeza de sobrevivência de sua obra pretérita são por ora a aquarela $\mathrm{S} /$ papel, de $22 \times 30 \mathrm{cms}$., de 1918 e um desenho à pena, de $13,5 \times 15$, da mesma época, ambos de propriedade da sra. Julia Behne (filha do crítico alemão Adolphe Behne), em Berlim.

10. Golyscheff queixava-se de não ter recebido de volta as obras que expusera em itinerantes da Novembergruppe (depoimento de 1965, cit.).

11. Anotações de Antonia Brede Golyscheff referem-se a "algumas invenções" de Golyscheff no terreno da química. Ele obtivera brevets na França. Golyscheff sobrevivera como químico em Paris durante parte da guerra (1940-42) e exercera essa profissão em Saint-Etienne (1946-9) e novamente em Paris (1950 e anos seguintes).

12. A exposição "Golyscheff obras recentes" foi realizada no Museu de Arte Contemporânea da Universidade São Paulo, de 8 de abril a 5 de maio de 1965 , acompanhada de um catálogo con dados diversos e ilustrações. Na abertura, foi apresentado o "Trio para cordas", a cargo da Orquestra de Câmara de São Paulo, sob a regência de Olivier Toni. Em maio-junho de 1975, o MAC-USP organizou nova mostra do artista.

13. Trata-se de Was ist der Dadaismus und was will er in Deutschland?, redigido por Hausmann e assinado por ele, Golyscheff e Huelsenbeck.

14. Cf. SCHUH, Willi "Thomas Mann's Doktor Faustus". Neue Zïrcher Zeitung, Zurique, $\mathrm{n}^{\circ} 2430,1947$.

15. Extrato do artigo: "A Jeff Golyscheff". Cf. nota supra n" 5. (Trad. do autor)

16. HAUSMANN, Raoul "Courrier Dada". Le Terrain Vague, Paris, p.46.

17. O próprio Golyscheff e Antonia Brede realizaram diligências na Europa para localizar telas, desenhos e objetos antigos, inutilmente. O mesmo se diga quanto às partituras.

18. WESCHER, Herta Collage, Nova York, Harry N. Abrams, 1968.

19. In Frankfurter Allgemeine Zeitung, Frankfurt, 27 abr. 1974. 
16 Revista Música, São Paulo, v.3, n.1:5-16 maio 1992

Walter Zanini é historiador de arte e professor titular do Departamento de Artes Plásticas da ECA-USP. 